\title{
ANALYSIS OF DECK SLAB OF REINFORCED CONCRETE GERBER-GIRDER BRIDGE WIDENED BY ADDITION OF CONTINUOUS STEEL-CONCRETE COMPOSITE GIRDERS
}

\author{
WOJCIECH SIEKIERSKI* \\ Dept of Bridges, Faculty of Civil and Environmental Engineering, \\ Poznan University of Technology, Poznan, Poland
}

Received 31 August 2018; accepted 26 March 2019

\begin{abstract}
Many Gerber-girder bridges have become obsolete in terms of deck width and load carrying capacity. If bridge replacement is not necessary, additional girders are installed. Sometimes, due to erection convenience, the added girders do not replicate the static scheme of the refurbished structure. Such an arrangement requires special attention to preserve structural durability. An example of the inappropriate arrangement of the widening of a Reinforced Concrete Gerber-girder road bridge is presented together with an alternative concept of refurbishment based on the addition of the continuous steel-concrete girders as the outermost ones. The added deck slab connects the added and the existing parts of the structure. Attention is drawn the static analysis of the added deck slab and the influence of the added outermost girders that do not replicate the static scheme of the existing ones. Due to different static schemes of the existing and the added girders, the traditional method of the deck slab analysis is inappropriate. The Finite Element 3D model is to be applied to access bending moments in the deck slab spans correctly. It is shown that: a) the analysis of the distribution of the bending moments in the existing and the added slab spans, especially near Gerber-hinges, should be based on the
\end{abstract}

\footnotetext{
* Corresponding author. wojciech.siekierski@put.poznan.pl 
Finite Element 3D modelling; b) the analysis should consider live loads acting on the whole width of the Gerber-hinge span; c) the bending moment distribution in the widened deck slab is sensitive to the distance to the Gerber hinge.

Keywords: analysis, bridge, concrete slab, deck widening, Finite Element Method (FEM), Gerber girder, refurbishment.

\section{Introduction}

Gerber-girder bridges were popular in the middle of the 20th century. Many of them were made of reinforced concrete (Szczygieł, 1972). Nowadays, the majority of them have become obsolete due to insufficient load carrying capacity and insufficient traffic flow capacity. The former problem is usually solved by the application of external prestressing (Bota \& Bota, 2016; Croci, Santoro, \& Macri, 1995; Hino, Tahara, \& Tsutsumi, 1999). The most popular solution to the latter problem is the addition of main girders (Hong \& Park, 2015; Mohammadi, Yakel, \& Azizinamini, 2014; Rybak, 1983). The added girders are connected to the existing span structure with cross bracing (Hong \& Park 2015; Mohammadi, Yakel, \& Azizinamini, 2014) or crossbeams (Nie, Wang, Zhang, Fan, \& Cai, 2012) or with deck slab only (Wen, 2011) and, in the majority of cases, their static scheme follows the static scheme of the existing girders.

The principle above was neglected in the case of the bridge shown in Figure 1. Its cross-section, static scheme and elevation are shown in Figure 2. Each of the outer spans consists of the cantilever (length $5.5 \mathrm{~m}$ ) and supported span (length $-9.0 \mathrm{~m}$ ). The Reinforced Concrete

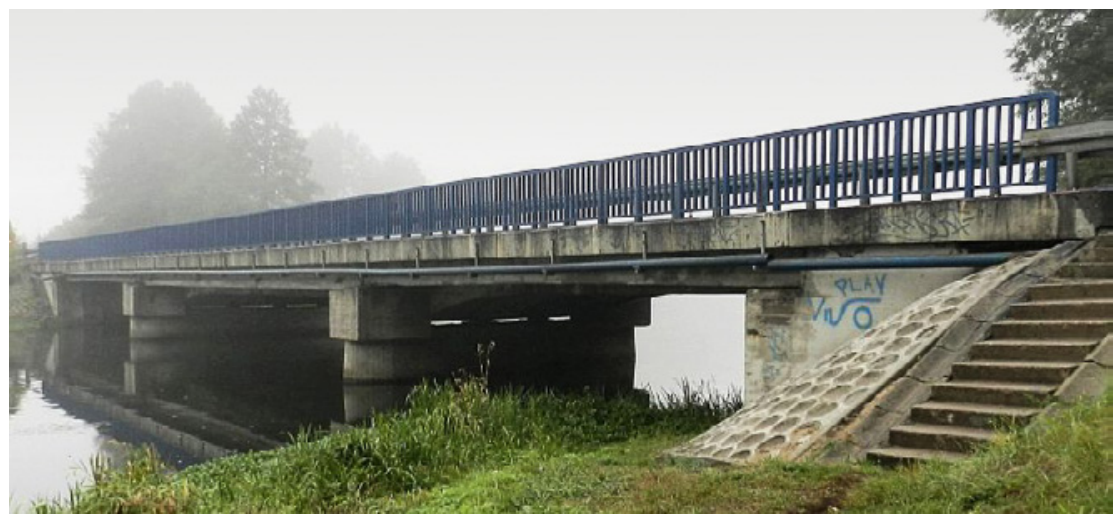

Figure 1. General view of the analysed bridge (photo A. Madaj) 

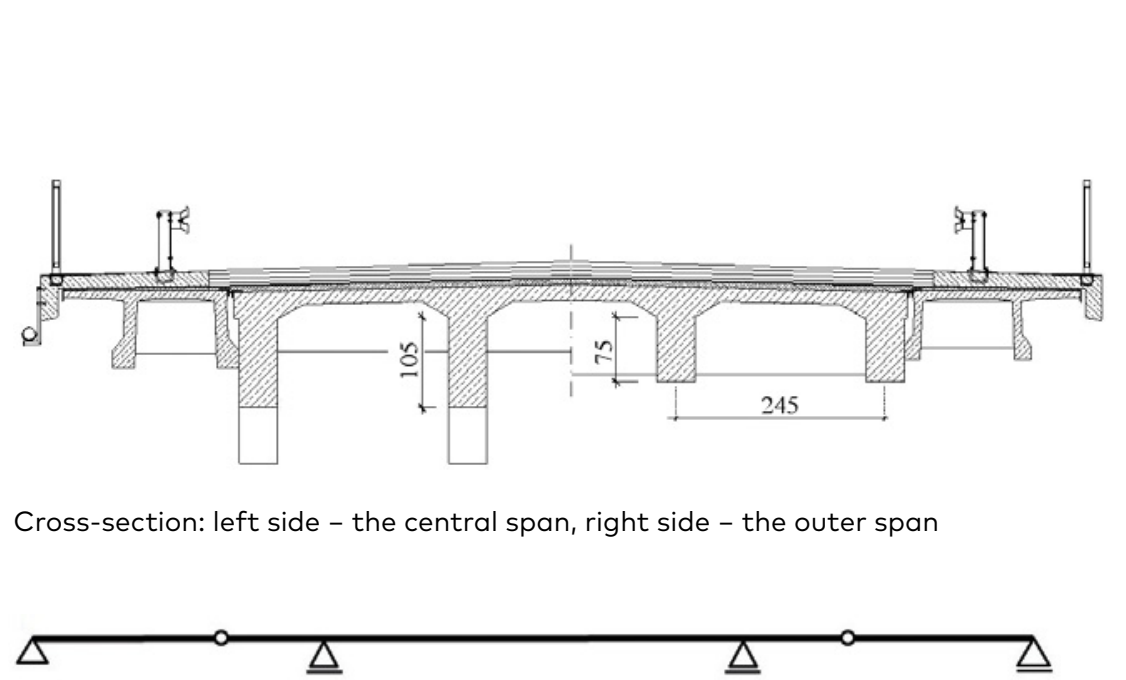

Static scheme (apart from the added П-girders, that are supported)

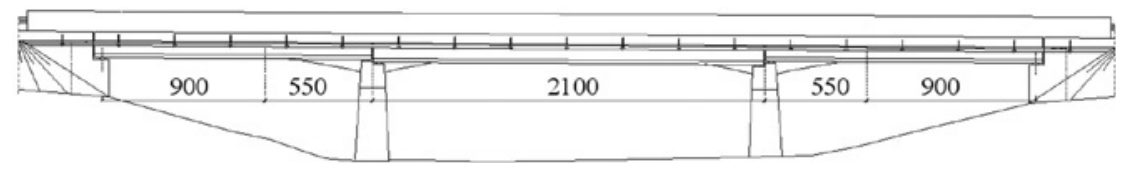

Elevation

Note: units in $\mathrm{cm}$.

Figure 2. The analysed bridge

(RC) girder height varies over a distance of $5.0 \mathrm{~m}$ near piers. The bridge was widened by replacing cantilevers protruding from the outermost girders with additional $\Pi$-girders made of prestressed concrete and supported on existing abutments and piers.

Due to variations in deflection lines of the outermost RC girders and the added prestressed girders, the longitudinal joint of the existing structure and the added girders lost its water tightness (Madaj, Mossor, \& Siekierski, 2017). The outermost RC girders experienced extensive damage (Figure 3) caused by leaks of water containing chlorides (Gode \& Paeglitis, 2014). Due to the close vicinity of the added $\Pi$-girders, the damaged regions of the outermost RC girders are hard to access and thus hard to repair.

The paper presents an alternative, more beneficial method of Gerbergirder span widening in terms of durability and overall load carrying capacity. Preliminary analysis of the refurbished structure, particularly the deck slab, is also presented. 


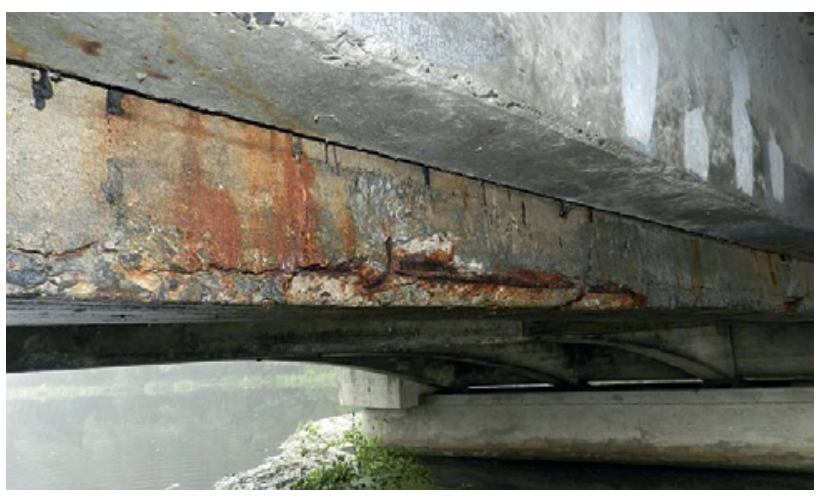

Note: concrete and reinforcement corrosion of the outermost RC girder.

Figure 3. The initially outermost Reinforced Concrete girder covered by the added $\Pi$-girder (photo A. Madaj)

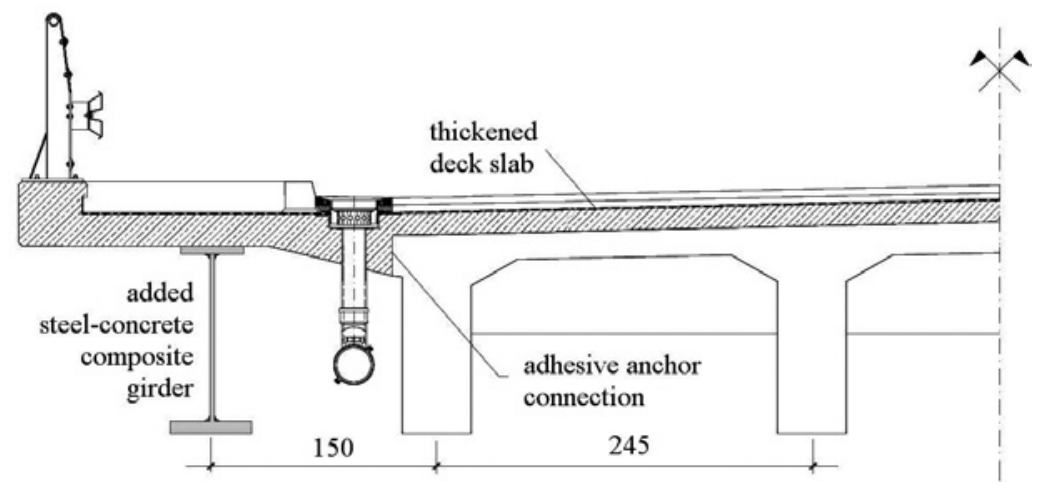

Note: the added concrete is dashed; units in $\mathrm{cm}$.

Figure 4. An alternative concept of the span widening

\section{Concept of deck slab widening}

As a result of the bridge inspection, an alternative method of the described span widening was suggested (Madaj, Mossor, \& Siekierski, 2017). It provides continuity of the deck slab together with the appropriate drainage system. The idea is based on introduction continuous steel beams as the outermost girders replacing the supported -girders. The girders are to be connected to the new concrete slab replacing existing cantilevers (Figure 4.) Moreover, the existing deck slab is to be thickened. 
The presented solution requires less labour on site during an erection in comparison to the installation of additional Gerber girders. Widening of the bridge span (added girders) is combined with enhancement of its load carrying capacity (thickened deck slab). There are no transverse stiffeners between the outermost RC girders and the added steelconcrete composite girders. The transverse stiffness is provided there only by the added deck slab that is connected to the outer face of the outermost RC girders (vertical interface) and the existing deck slab (horizontal interface) with adhesive anchors and added reinforcement.

The added deck slab needs to be able to sustain the effects of different deflection layouts of the outermost Gerber girders and the added continuous girders. The paper investigates the static behaviour of the deck slab in the region of the Gerber hinges. An analytical method and Finite Element Method (FEM) are applied to assess the bending moments of the slab perpendicular to the span axis.

\section{Analysis of the added deck slab}

\subsection{Classic technique}

Girders support the deck slab. In the outer spans of the bridge, the boundary conditions for the outermost slab span differ from one girder to the other and vary along the span. Firstly, the outermost girder of the initial structure is a Gerber girder, whereas the added girder is a continuous girder. Secondly, the flexural stiffness of the two girders is similar near the supports, whereas, at Gerber hinges, it is significantly different.

Review of methods of bridge deck analysis is given by Cusens \& Pama (1975) and Hambly (1991). For most structures the equivalent strip analysis or the grillage analysis are appropriate.

The equivalent strip method for RC deck slabs analysis is based on classical beam theory applied to flexure of the slab in the transverse

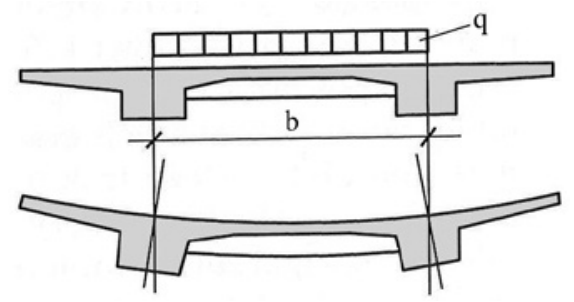

Figure 5. Girder torsion implied by deck slab flexure under local loading
Gerber-Girder

Bridge Widened

by Addition

of Continuous

Steel-Concrete

Composite Girders 
direction. Provided girders of modest torsional rigidity support the slab the strip is treated as a continuous beam (or a simply supported beam if appropriate), assuming pinned supports at the centre of each girder. Presence of the crossbeams makes deck slab support conditions to vary along the span, primarily due to variation in the torsional constraint of the girders.

The assumption that the torsional constraint of girders is critical for the analysis of RC deck slab gave rise to a modification of the equivalent strip method (Holst, 1993). Its concept is based on the degree of slab flexural restraint $(\alpha)$ provided by a supporting girder (Figure 5 ). The restraint depends on the structural arrangement and varies along the bridge span, by the crossbeam layout. The value of is computed as follows:

$$
\alpha=\frac{1}{1+\frac{k l^{2}}{b} \cdot \frac{I_{s}}{I_{T}}},
$$

where $\alpha$ - degree of slab flexural restraint; $I_{s}$ - slab moment of inertia in bending, $\mathrm{m}^{4} ; I_{T}$ - girder moment of inertia in torsion, $\mathrm{m}^{4} ; b$-girder axial spacing, $\mathrm{m} ; l$ - cross-beam axial spacing, $\mathrm{m} ; k$ - a coefficient is accounting for the distance of given location to the nearest cross-beam (Table 1).

Bending moments in the slab span and at the slab, support are computed as follows:

- bending moment at the support (girder):

$$
M_{e l . s u}=\alpha \bar{M}_{s u} ;
$$

- bending moment in the mid-span:

$$
M_{e l . s p}=M_{s p}-\alpha\left(M_{s p}-\bar{M}_{s p}\right) .
$$

where $\alpha$ - degree of slab flexural restraint at the support; $\bar{M}_{s u}$, $\bar{M}_{s p}$ - bending moments at the support, and in the mid-span respectively, for a fixed beam, kNm; $M_{s p}$ - a bending moment in the mid-span, for a simply supported beam, $\mathrm{kNm}$.

Table 1. Principle for setting the coefficient

\begin{tabular}{lllllll}
\hline$\frac{x}{l}$ & 0.000 & 0.100 & 0.200 & 0.300 & 0.400 & 0.500 \\
$k$ & 0.000 & 0.225 & 0.400 & 0.525 & 0.600 & 0.625 \\
\hline
\end{tabular}

Note: $x$ - the distance to the nearest crossbeam. 


\subsection{Numerical analysis}

Gerber-Girder

Bridge Widened

by Addition

Finite Element modelling is usually applied in bridge analysis (Fu \& Wang, 2015). This technique is able to take into account the of Continuous Steel-Concrete influence of the torsional and the flexural rigidities of girders on the behaviour of the deck slab. The Finite Element model of the widened bridge span (initial arrangement together with additional steel-concrete girders) was created in Autodesk Robot environment (Marsh, 2016). It is shown in Figure 6. RC and steel girder ribs, as well as crossbeams, were modelled with 2-node beam elements of 6 degrees of freedom per node while the deck slab was modelled with 4-node shell elements of 6 degrees of freedom per node. Elastic material behaviour and small strains were assumed. Beam and shell elements were situated in the centre plane of the deck slab. For the girders and crossbeams, appropriate eccentricities were declared to the actual location of their centre of gravity axes (Fu \& Wang, 2015). The deck slab, after refurbishment, was assumed to be $30 \mathrm{~cm}$ thick within the existing part (including $12 \mathrm{~cm}$ of added concrete) and $20 \mathrm{~cm}$ thick within the added part. The Flexural Stiffness (EI) of RC girder, by the stiffness of the added steel-concrete composite girder, was: 0.60 in the side spans, 1.16 in the middle span and 3.28 at piers. The EI of the steel beam itself, by the stiffness of the steel-concrete composite girder, was 0.33 . Modulus of elasticity for the existing concrete is $30 \mathrm{GPa}$ (B30 - classification until 2010), for the added concrete - $32 \mathrm{GPa}(\mathrm{C} 30 / 37)$ and for the structural steel - $210 \mathrm{GPa}$.

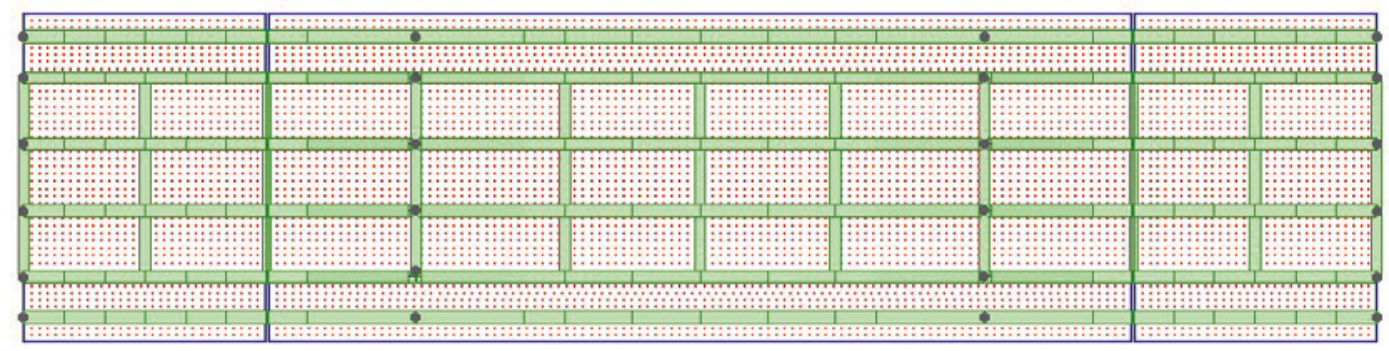

- the deck slab boundaries and location of the Gerber hinges within the outer spans (apart from the added steel beams);

location of the beam elements modelling girders and cross-beams;

bearings.

Note: the cross-beams are present only between the RC girders.

Figure 6. Bottom view of the Finite Element 
Two load cases of uniformly distributed load (UDL) of $10 \mathrm{kN} / \mathrm{m}^{2}$ over the whole length of the outer span of the bridge were considered:

- A - applied to the outermost slab span (between the outermost RC girder and the added steel-concrete composite girder); it is meant to reflect the traditional approach to the deck slab analysis,

- B - applied to all slab spans.

The assumed load cases were chosen to present certain phenomena instead of following loading rules given in bridge design standards.

\section{Deck slab analysis results}

\subsection{Analysis lengthwise}

Diagrams of bending moment in the mid-span and at the support of the added slab span, computed according to the analytical and numerical methods, are shown in Figure 7. The symbols are:

- $M_{s u-a}, M_{s p-a}$ - the bending moment at the support and in the midspan respectively, by the analytical method;

- $\quad M_{s u-n A}, M_{s p-n A}$ - the bending moment at the support and in the midspan respectively, according to the numerical analysis of the load case A;

- $M_{s p-n B}$ - the bending moment in the mid-span, according to the numerical analysis of the load case $B$.

While computing the degree of slab flexural restraint $\alpha$ it was assumed that at supports the steel-concrete composite girders are restrained against torsion due to the existence of bearings.

The assessment based on the degree of the slab flexural restraint underestimates the slab bending moments at the RC girder $\left(M_{s u-a}\right.$ a diagram in Figure 4) near the abutment and the pier in comparison to the respective FEM results $\left(M_{s u-n A}\right.$ diagram). The bending moment in the added slab mid-span at Gerber hinge, suggested by the analytical method, is also underestimated. By the numerical analysis, generally, the slab bending moments at the RC girder $\left(M_{s u-n A}\right.$ diagram) are larger than at the steel-concrete composite girder. The only exception is the ordinate 9.0 that denotes the location of Gerber hinge in the RC girder (the single orange dot in blue circle). The FEM analysis shows that, near the Gerber hinge, the sagging bending of the deck slab at the outermost RC girder is small ( $M_{\text {su-nA }}$ diagram). Local increase of bending moment in the added slab mid-span $\left(M_{s p-n A}\right.$ diagram) is seen near the Gerber hinge.

The sagging bending of the added slab span is more explicit when all span slabs are loaded (load case B). The diagram of bending moment in 


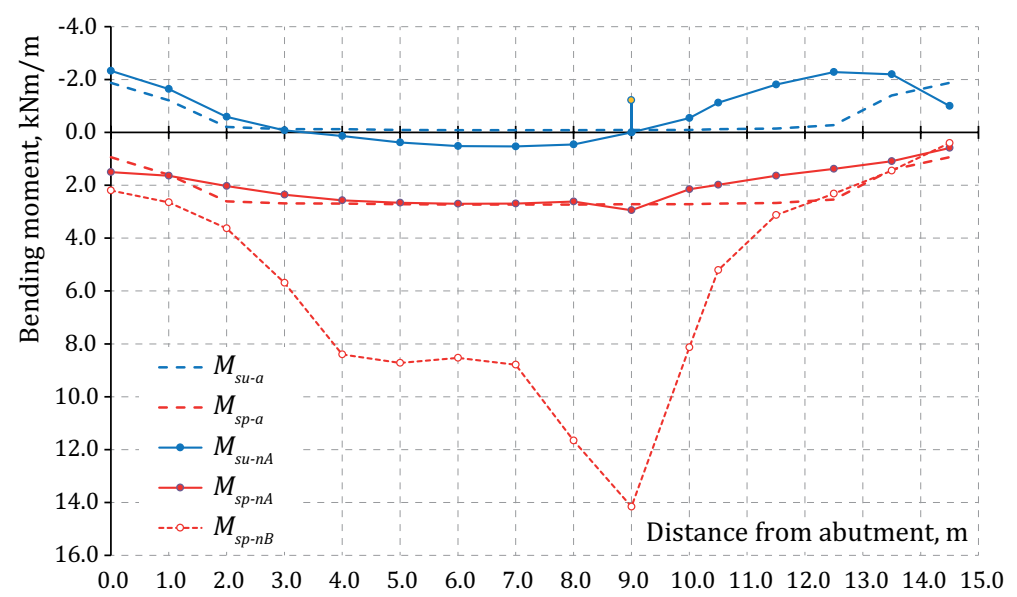

Note: the horizontal axis ordinate 9.0 refers to the Gerber hinge location

Figure 7. Bending moments in the added deck slab

the added slab mid-span $\left(M_{s p-n B}\right.$ diagram) shows that the outermost slab spans carry loads located on the whole width of the simply supported portion of the outer bridge span. The bending moments due to this action are much larger than those based on the analytical method. The magnitude of the bending moments depends on the flexural rigidity of the steel-concrete composite girders. The more rigid the beam, the larger the bending moments in the added slab span.

\subsection{Analysis crosswise}

Figure 8 shows the distribution of the bending moments in the deck slab for the load case B (UDL applied to all slab spans) in the selected cross-sections of the Gerber-hinge span. The symbols are:

- 1 - location of the added continuous girder;

- 2 - location of the outermost Gerber girder;

- 3 - location of the inner Gerber girder;

- $x$ - in the diagram, description gives the distance from the support at the abutment to the given cross-section.

It corresponds to the ordinates in Figure 7. Extreme vertical axis ordinates of the diagrams in the outermost spans are related to the vertical axis ordinates of the $M_{s p-n B}$ diagram in Figure 7.

The three bending moment diagrams are given in Figure 8 and show how the different static schemes of the existing and the added girders influence the behaviour of the deck slab - the added are continuous
Gerber-Girder

Bridge Widened

by Addition

of Continuous

Steel-Concrete

Composite Girders 
girders (1) while the existing are Gerber girders (2 and 3). The diagram for $x=2.0 \mathrm{~m}$ shows that near the abutment the rigidity provided by the girders - the deck slab supports - is similar: there is sagging bending in all the slab spans and hogging bending over the RC girders. At the distance of 2 meters away from the Gerber hinge $(x=7.0 \mathrm{~m})$ the difference in the slab support rigidity is noticeable - the added girders carry loads situated on two external slab spans on each deck side (the spans covered by the sagging bending). Near the Gerber hinge $(x=8.5 \mathrm{~m})$ the outermost (added) girders carry loads situated on all slab spans what is reflected by the extent of the sagging bending. The difference in the bending moments observed in the added, and the existing slab spans are enhanced due to the close vicinity of the cross-beam at the Gerber hinge. In the existing spans, the deck slab transfers the UDL in two orthogonal directions, towards the adjacent girders and the crossbeam, while in the outermost (added) spans - only towards the adjacent girders.

It is possible to reduce the extent and magnitude of the sagging bending of the widened deck slab by reduction of the flexural rigidity of the added girders. However, such action will also reduce the efficiency of the strengthening of the existing bridge span. In any case, the flexural rigidity of the added continuous girders is an important factor of successful span widening design.

The deflection lines of the main girders obtained for the load case B shown Figure 9 support the observations made concerning Figure 8. Red dots mark the location of the cross-sections shown in Figure 8. Girder numbers match those given in Figure 8. The deflection of the outermost continuous girder (1) is significantly smaller than the deflections of the RC Gerber girders (2 and 3) that are similar. The reason for this is lack of cross-bracing between the added girders (1) and the outermost existing girders (2) combined with the presence of the crossbeams between the outermost (2) and the inner (3) existing girders.

The introduction of the outermost continuous girders alters the bending moment distribution in the deck slab across and along the Gerber-hinge span. The reinforcement of the existing deck slab needs to be checked if it is capable of sustaining the sagging bending. When necessary and if possible, the reinforcement has to be adjusted. The additional reinforcement is likely to be non-uniformly distributed along the span.

The analysis of load transverse distribution at the Gerber hinge before and after the refurbishment has been carried out to make a general assessment of the effectiveness of the presented solution. The 


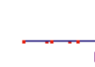

$1+2$

\section{3}

$x=2.0 \mathrm{~m}$

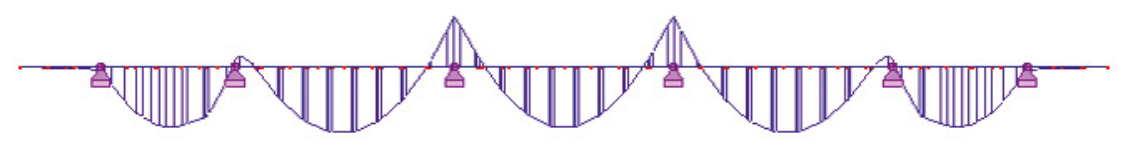

$x=7.0 \mathrm{~m}$

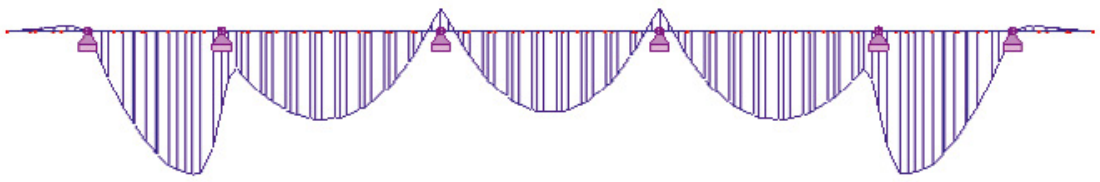

$x=8.5 \mathrm{~m}$

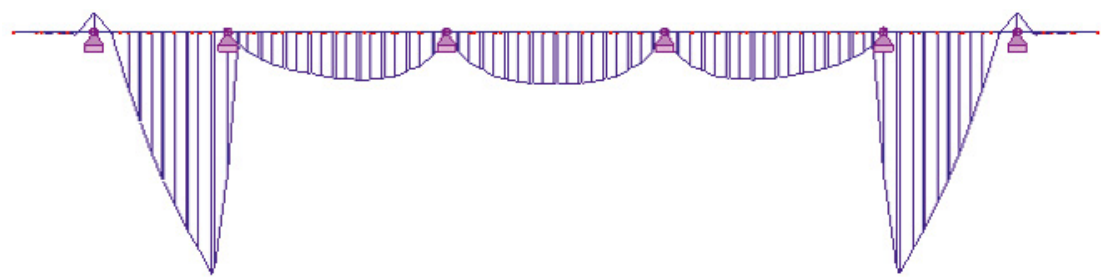

Note: the Gerber hinge is at $x=9.0 \mathrm{~m}$

Figure 8. Distribution of bending moments in the deck slab cross-sections for the load case B

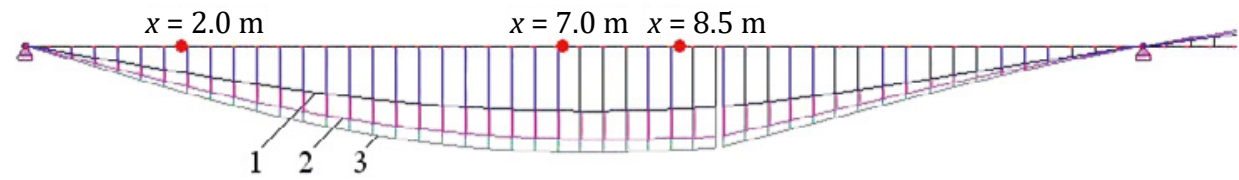

1 - the added continuous girder,

2 - the outermost Gerber girder,

3 - the inner Gerber girder.

Note: the diagram numbers and the ordinates comply with the descriptions in Figure 8.

Figure 9. Deflection lines of the main girders in the Gerber-hinge span for the load case B 


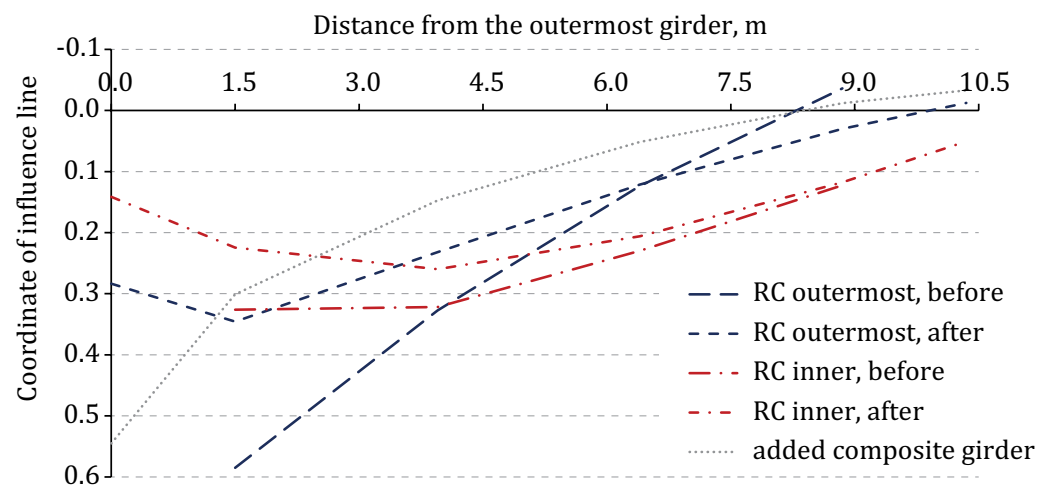

Figure 10. Influence lines of load transverse distribution before and after refurbishment

Table 2. Comparison of load transverse distribution before and after refurbishment

\begin{tabular}{|c|c|c|c|c|c|c|c|}
\hline \multirow[b]{2}{*}{ Girder } & \multicolumn{3}{|c|}{$R C$ outermost } & \multicolumn{3}{|c|}{$R C$ inner } & \multirow[b]{2}{*}{$\begin{array}{l}\text { Added } \\
\text { composite }\end{array}$} \\
\hline & before & after & $\begin{array}{l}\text { change* } \\
\frac{(3)-(2)}{2}\end{array}$ & before & after & $\begin{array}{l}\text { change* } \\
\frac{(6)-(5)}{5}\end{array}$ & \\
\hline (1) & (2) & (3) & (4) & (5) & (6) & (7) & (8) \\
\hline Maximum ordinate, - & 0.585 & 0.346 & $-41 \%$ & 0.326 & 0.260 & $-20 \%$ & 0.545 \\
\hline $\begin{array}{l}\text { Area under positive } \\
\text { part of the diagram, } m\end{array}$ & 1.788 & 1.813 & $1 \%$ & 1.900 & 1.961 & $3 \%$ & 1.479 \\
\hline
\end{tabular}

Note: * negative sign denotes decrease after refurbishment.

uniformly distributed load was applied subsequently to each girder over the outer span (the Gerber-hinge span). The influence lines created based on recorded vertical displacements are shown in Figure 10. The maximum ordinate and the area under the positive part of each diagram are put together in Table 2 . The refurbishment leads to a significant decrease $(41 \%$ and $20 \%$ ) of the maximum ordinate of the influence lines for the RC girders and a small increase $(1 \%$ and $3 \%$ ) of the area under the positive part of the diagrams. It means that the maximum loading carried by the RC girders is very likely to be reduced after refurbishment. 


\section{Conclusions}

The following comments are made after the completion of the analyses:

1. In the case of widening of an RC Gerber-girder bridge by addition of continuous girders, particular attention should be paid to bending moment distribution in the existing deck slab since it is altered due to different static schemes of girders.

2. The assessment of the distribution of bending moments in the existing and the added slab spans, especially near Gerber hinges, should be based on Finite Element 3D analysis. In this way, the influence of the variations of the flexural and torsional stiffness of the existing and the added girders are considered.

3. The analysis should consider live loads acting on the whole width of the Gerber-hinge span. Considering live loads only over the added deck slab span leads to significant underestimation of the magnitude of bending moments.

4. The bending moment distribution in the widened deck slab is sensitive to the distance to the Gerber hinge. Near the hinge, the deck slab may require additional longitudinal and transverse reinforcement.

5. Since the paper focuses on bending moments, it must be noted that additional shear in the deck slab, implied by the presented solution, also needs to be controlled.

6. Examining the presented results, one should keep in mind that the internal force distribution induced by the solution is sensitive to the combination of the stiffness of the existing and the added parts of the structure.

\section{REFERENCES}

Bota, A., \& Bota, D. (2016). What means external prestressing for an old Gerber structure. Procedia engineering, 156, 48-53. https://doi.org/10.1016/j.proeng.2016.08.266

Croci, G., Santoro, V. M., \& Macri, F. (1995). Structural rehabilitation of a reinforced concrete and a prestressed concrete bridge. IABSE reports, 73/1/73/2, 77-82.

Cusens, A. R., \& Pama, R. P. (1975). Bridge deck analysis.

Fu, C. C., \& Wang, S. (2015). Computational analysis and design of bridge structures. CRC Press.
Concrete

Gerber-Girder

Bridge Widened

by Addition

of Continuous

Steel-Concrete

Composite Girders 
Gode, G., \& Paeglitis, A. (2014). Concrete bridge deterioration caused by de-icing salts in high traffic volume road environment in Latvia. Baltic Journal of Road and Bridge Engineering, 9(2), 200-207.

https://doi.org/10.3846/bjrbe.2014.25

Hambly, E. C. (1991). Bridge deck behaviour. CRC Press.

Hino, S., Tahara, Y., \& Tsutsumi, T. (1999). Strengthening for an existing RC Gerber bridge using external cables. IABSE reports, 83, 236-237.

Holst, K. H. (1993). Brücken aus Stahlbeton Und Spannbeton. Entwirf, Konstruktion Und Berechnung. Ernst \& Sohn. Berlin. (in German)

Hong, S., \& Park, S. K. (2015). Effect of vehicle-induced vibrations on early-age concrete during bridge widening. Construction and Building Materials, 77, 179-186. https://doi.org/10.1016/j.conbuildmat.2014.12.043

Madaj, A., Mossor, K., \& Siekierski, W. (2017). Mosty z przęsłami przegubowymitrwałość i warunki użytkowania na przykładzie wybranych obiektów. Archives of Institute of Civil Engineering, 24, 187-204. https://doi.org/10.21008/j.1897-4007.2017.24.14 (in Polish)

Marsh, K. (2016). Autodesk Robot Structural Analysis Professional 2016: essentials. Marsh API.

Mohammadi, A., Yakel, A., \& Azizinamini, A. (2014). Phase and widening construction of steel bridges (No. BDK80-977-28). Florida International University.

Nie, J. G., Wang, Y. H., Zhang, X. G., Fan, J. S., \& Cai, C. S. (2012). Mechanical behavior of composite joints for connecting existing concrete bridges and steel-concrete composite beams. Journal of Constructional Steel Research, 75, 11-20. https://doi.org/10.1016/j.jcsr.2012.02.019

Rybak, M. (1983). Przebudowa i wzmacnianie mostów. Wydawnictwa Komunikacji i Łączności. (in Polish)

Szczygieł, J. (1972). Mosty z betonu zbrojonego i sprężonego. Wydawnictwa komunikacji i łączności. (in Polish)

Wen, Q. J. (2011). Long-term effect analysis of prestressed concrete box-girder bridge widening. Construction and Building Materials, 25(4), 1580-1586. https://doi.org/10.1016/j.conbuildmat.2010.09.041 